\title{
KEMAMPUAN MEMBACA SISWA KELAS IX SMP NEGERI 1 DAN SMP NEGERI 3 MARABAHAN
}

\author{
ABILITY READING STUDEN \\ OF CLASS IX SMP NEGERI 1 AND SMP NEGERI 3 MARABAHAN
}

\author{
Yosi Khairunnisa; Jumadi; Ahsani Taqwiem \\ Program Studi Pendidikan Bahasa Indonesia \\ FKIP Universitas Lambung Mangkurat \\ yosikhairunnisa02@gmail.com
}

\begin{abstract}
Abstrak
Penelitian yang mengkaji kemampuan membaca peserta didik di Marabahan bertujuan untuk mendeskripsikan, (a) kemampuan membaca pemahaman peserta didik, (b) kemampuan membaca kritis peserta didik, (c) perbedaan kemampuan membaca kritis antara peserta didik SMP Negeri 1 dan SMP Negeri 3 Marabahan, dan (d) hubungan membaca pemahaman dengan membaca kritis peserta didik. Jenis penelitian kuantitatif dengan metode dekriptif. Populasi penelitian peserta didik kelas IX SMP Negeri 1 dan SMP Negeri 3 Marabahan. Sampel penelitian peserta didik SMP Negeri 1 Marabahan dengan responden 91 peserta didik. Sampel penelitian peserta didik SMP Negeri 3 Marabahan dengan responden 77 peserta didik. Teknik pengumpulan data yang digunakan 25 tes objektif dan 4 tes subjektif. Berdasarkan hasil penelitian dapat disimpulkan bahwa kemampuan membaca peserta didik kelas IX SMP Negeri 1 dan SMP Negeri 3 Marabahan dalam kategori rendah dengan rata-rata 57,50.
\end{abstract}

Kata kunci: Kemampuan, membaca pemahaman, dan membaca kritis.

\begin{abstract}
The purpose of this research about ability reading of students in Marabahan is to describe things, (a) ability understand reading of students, (b) ability critical reading of students, (c) difference ability critical reading between students of SMP Negeri 1 and SMP Negeri 3 Marabahan, and (d) relationship understand reading with critical reading of students. This type of research is quantitative with descriptive method. The population is student of class IX SMP Negeri 1 and SMP Negeri 3 Marabahan. The sample students of class IX SMP Negeri 1 Marabahan is 91 respondens. The sample students of class IX SMP Negeri 3 Marabahan is 77 respondens. The technique of collecting data is 25 objective tests and 4 subjective tests. Based on the research can be concluded that ability reading students of class IX SMP Marabahan in the low category with an average of 57,50.
\end{abstract}

Keyword: Ability, understand reading, critical reading. 


\section{Pendahuluan}

Peneliti melakukan penelitian ini karena memerhatikan pentingnya pendidik mengetahui kemampuan membaca yang dimiliki oleh masing-masing peserta didik. Selain itu, alasan peneliti melakukan penelitian tersebut karena untuk mengamati kemampuan membaca para siswa di Kalimantan Selatan dan pentingnya kemampuan membaca diterapkan di Sekolah terutama terkait dengan penelitian kemam-puan membaca kritis.

Alasan melakukan pene-litian di SMPN Marabahan, yakni (1) ada masalah bersama yang dikemukakan pemerintah Barito Kuala untuk dicari solusinya, yakni berkaitan dengan hasil UN yang selama ini diperoleh siswa. Rendahnya hasil UN para siswa dapat dipre-diksi berkorelasi dengan penguasaan materi, termasuk di dalamnya masih rendahnya kemampuan membaca para siswa, dan (2) informasi yang sangat diperlukan untuk memperbaiki kualitas pembelajaran bahasa Indonesia di Kalimantan Selatan, terutama terkait dengan peningkatan kemampuan membaca peserta didik. Sekolah di marabahan termasuk tempat terpencil, jauh dari kota, daerah perairan. Dari tempat dan keadaan seperti itu kurangnya kemampuan membaca kritis peserta didik berdasarkan hasil Ujian Nasional bidang bahasa Indonesia tahun sebelumnya. Hal itu juga, sesuai fakta dari hasil kerja peserta didik telah diberi soal pilihan ganda dan uraian.

Berdasarkan fakta, alasan, dan pemikiran yang telah diuraikan tersebut, penelitian yang berjudul "Kemam-puan Membaca Siswa Kelas IX SMP Negeri 1 dan SMP Negeri 3 Marabahan Kabupaten Barito Kuala" ini perlu dilakukan. Hipotesis diambil berdasarkan tingkat sekolah. SMP Negeri 1 Marabahan dikategorikan kemampuan membaca tinggi dikarenakan sekolah favorit dan terkenal lebih cerdas daripada sekolah lainnya. Untuk SMP Negeri 3 Marabahan dikategorikan sedang sebabnya kebalikan dari SMP Negeri 1 Marabahan sekolah yang tidak favorit.

Ada beberapa penelitian membahas tentang membaca seperti, membaca pemahaman, membaca cepat, jenis membaca, teknik membaca, membaca cerpen, membaca puisi, membaca novel, membaca pantun, membaca legenda, dongeng, cerita rakyat dan jenis penelitian membaca lainnya. Tetapi, penelitian mengenai membaca kritis hanya beberapa. Apalagi penelitiannya di Kalimantan Selatan. Oleh karena itu, peneliti mengambil judul Kemampuan Membaca Peserta Didik di Marabahan Kabupaten Barito Kuala. Kebannyakan adalah penelitian tindakan kelas. 
Manfaat untuk peneliti mendapatkan informasi dan sebagai ancangan peneliti akan menjadi pendidik. Agar tahu kendala dari penelitian akan diatasi dengan melakukan perbaikan. Selain itu, manfaat untuk pendidik akan mendapatkan informasi agar lebih aktif dan kreatif untuk meningkatkan proses membaca peserta didik. Baik itu, dari bahan buku bacaan diperbanyak. Tentunnya buku-buku sesuai di jenjang SMP. Manfaat untuk peserta didik agar semakin meningkat minat membacanya. Selain itu, dapat meningkatkan dan menambah wawasan dari membaca sekadar hiburan sampai dengan membaca kritis.

\section{Metode Penelitian}

\section{Jenis Penelitian}

Penelitian deskriptif kuantitatif yakni penelitian yang akan menggambarkan suatu hal dari data yang bersifat kuantitatif.

\section{Waktu dan Tempat Penelitian}

Penelitian ini, dilaksanakan pada 12 November 2018. Adapun tempat penelitian dilaksanakan di 2 SMP yang ada di Kabupaten Barito Kuala. Berikut tabel 1 dan 2 tempat penelitian dan waktu penelitian dilaksanakan.

Tabel: Tempat Penelitian Survai

\begin{tabular}{|l|l|l|}
\hline NO & TEMPAT & ALAMAT \\
\hline
\end{tabular}

\begin{tabular}{|c|l|l|}
\hline 1 & $\begin{array}{l}\text { SMP Negeri 1 } \\
\text { Marabahan }\end{array}$ & $\begin{array}{l}\text { Marabahan, } \\
\text { Kabupaten Barito } \\
\text { Kuala, Kalimantan } \\
\text { Selatan 70513 }\end{array}$ \\
\hline 2 & $\begin{array}{l}\text { SMP Negeri 3 } \\
\text { Marabahan }\end{array}$ & $\begin{array}{l}\text { No. 75, Ulu } \\
\text { Benteng, Barito } \\
\text { Kuala, Kabupaten } \\
\text { Barito Kuala, } \\
\text { Kalimantan Selatan } \\
\text { 70513 }\end{array}$ \\
\hline
\end{tabular}

\section{Populasi dan Sampel Penelitian}

Populasi dalam penelitian ini adalah peserta didik kelas IX SMP Negeri 1 dan SMP Negeri 3 Marabahan di Kabupaten Barito Kuala Tahun Ajaran 2018/2019. Dari populasi penelitian tersebut dilakukan sampel acak, yaitu subjeknya setingkat atau sama-sama kelas IX SMP (Arikunto, 2002: 111). Penelitian ini mengambil sampel sebanyak 7 kelas, yakni kelas IX A sampai C SMPN 1 sebaliknya kelas IX A sampai kelas D.

\section{Teknik Pengumpulan Data}

Penelitian tentang kemampuan membaca yang digunakan adalah tes. Tes dimaksud berupa objektif yang terdapat 4 
pilihan pada satu pertanyaan ber-tujuan mengetahui kognitif pembaca dan tes subjektif berjumlah 4 butir soal bertujuan melengkapi data peneliti dan mengetahui kemampuan membaca kritis pembaca dengan jawaban panjang (Arikunto 2012:46).

\section{Teknik Analisis Data}

Senin, 12 November 2018 pukul 07:00 WITA menuju SMP Negeri 3 Marabahan untuk melakukan penelitian "Kemam-puan Membaca Peserta Didik

\begin{tabular}{|c|c|c|c|c|c|c|}
\hline \multirow[b]{2}{*}{$\begin{array}{l}\text { Kem. } \\
\text { Memb } \\
\text { aca }\end{array}$} & \multicolumn{3}{|c|}{$\begin{array}{ll}\text { SMPN } & 1 \\
\text { Marabahan }\end{array}$} & \multicolumn{3}{|c|}{$\begin{array}{l}\text { SMPN } \\
\text { Marabahan }\end{array}$} \\
\hline & $\mathrm{N}$ & $\begin{array}{l}\mathrm{Re} \\
\text { rat } \\
\mathrm{a}\end{array}$ & $\begin{array}{l}\text { Stand } \\
\text { ar } \\
\text { devia } \\
\text { si }\end{array}$ & $\mathrm{N}$ & $\begin{array}{l}\mathrm{Re} \\
\mathrm{rat} \\
\mathrm{a}\end{array}$ & $\begin{array}{l}\text { Stand } \\
\text { ar } \\
\text { devia } \\
\text { si }\end{array}$ \\
\hline $\begin{array}{l}\text { Pem } \\
\text { aha } \\
\text { man }\end{array}$ & 91 & $\begin{array}{l}68, \\
00\end{array}$ & 10,73 & 71 & $\begin{array}{l}57 \\
77\end{array}$ & 11,17 \\
\hline $\begin{array}{l}\text { Kriti } \\
\text { s }\end{array}$ & 91 & $\begin{array}{l}54, \\
10\end{array}$ & 13,95 & 71 & $\begin{array}{l}49, \\
26\end{array}$ & 16,43 \\
\hline
\end{tabular}

Kelas IX SMP Negeri 1 dan SMP Negeri 3

Marabahan Kabupaten Barito Kuala”.

a. Bertemu pihak SMPN 1 dan berbagi memasuki kelas IX terdiri dari 4 kelas.

b. Setelah mengerjakan instrument, peneliti ke perpustakaan. c. Pukul 11:15 WITA melakukan penelitian ke SMP Negeri 1 Marabahan dan bertemu pihak sekolah.

d. Setelah mendapatkan izin memasuki ruangan untuk membagikan instrument penelitian ke peserta didik.

e. Kembali ke kantor bertemu pihak sekolah untuk meminta surat rekomendasi penelitian.

f. Dalam jangka waktu 2 hari peneliti melakukan koreksi terhadap jawaban siswa tentang pertanyaan bacaan, baik pertanyaan bacaan pilihan ganda maupun uraian.

g. Memeriksa hasil kerja peserta didik sesuai dengan bobot yang telah di-tetapkan.

h. Menentukan tingkat kemampuan, yang mencakup (a) menentukan kemampuan membaca kompre-hensif pada masingmasing sekolah dan seluruh sekolah serta perbandingan kemampuan dari kedua sekolah; (b) menentukan kemampuan membaca kritis dan pemahaman siswa.

Pada masing-masing siswa dan pada masing-masing sekolah serta menentukan perbandingan kemampuan membaca kritis dari kedua sekolah; dan menentukan ada tidaknya korelasi antara tingkat kemampuan membaca komprehensif dengan tingkat kemampuan membaca kritis. Perhitungan dari semua 
masing-masing tingkat kompensidan korelasi itu menggunakan SPSS.

\section{Hasil Penelitian dan Pembahasan}

\section{A. Hasil Analisis Statistik}

\section{Deskripsi Kemampuan Membaca}

\section{Siswa}

Output SPSS untuk analisis deskriptif terhadap kemampuan membaca pemahaman dan membaca kritis siswa SMPN 1 Marabahan dan SMPN 3 Marabahan ada pada lampiran 1.

1. Kemampuan membaca pemahaman siswa SMPN 1 Marabahan

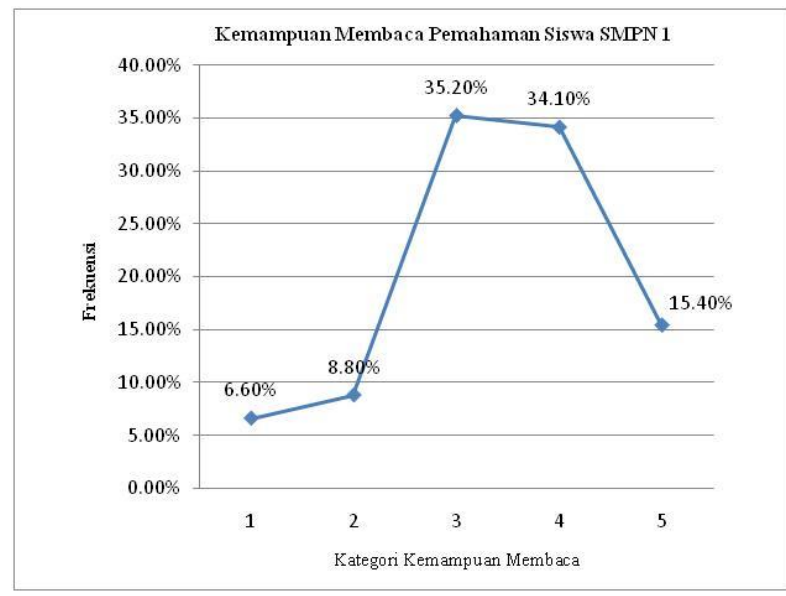

Grafik di atas 49,5\% siswa SMPN 1 Marabahan kemampuan membaca pemahamannya kategori tinggi dan sangat tinggi. Modus dari kemam-puan membaca pemahaman siswa adalah kategori sedang, yaitu sebesar 35,2\%. Berdasarkan modus diagram di atas dapat disimpulkan bahwa kecenderungan kemampuan membaca pemahaman siswa berkategori sedang. Simpulan ini didukung dengan rata-rata kemampuan membaca pemahaman siswa yang terdapat pada Tabel, yaitu sebesar 68,0 yang menunjukkan bahwa kemampuan membaca pemahaman siswa SMPN 1 Marabahan berada pada kategori sedang.

2. Kemampuan membaca kritis siswa SMPN 1 Marabahan

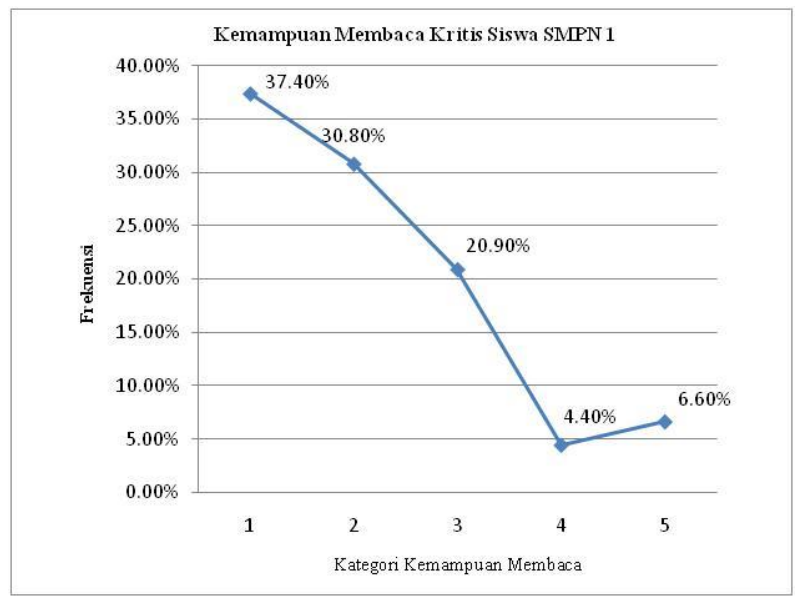

Grafik di atas 68,20\% siswa SMPN 1 Marabahan kemam-puan membaca kritisnya berkategori rendah dan sangat rendah. Hanya $11,00 \%$ siswa yang memiliki kemampuan membaca kritis pada kategori tinggi dan sangat tinggi. Berdasarkan diagram di atas dapat disimpulkan bahwa kecenderungan kemampuan membaca kritis siwa berada pada ketegori rendah. Tabel menunjukkan 54,10 yakni kemampuan me- 
mbaca kritis siswa SMP Negeri 1 Marabahan berkategori rendah.

3. Kemampuan membaca pemahaman siswa SMPN 3 Marabahan

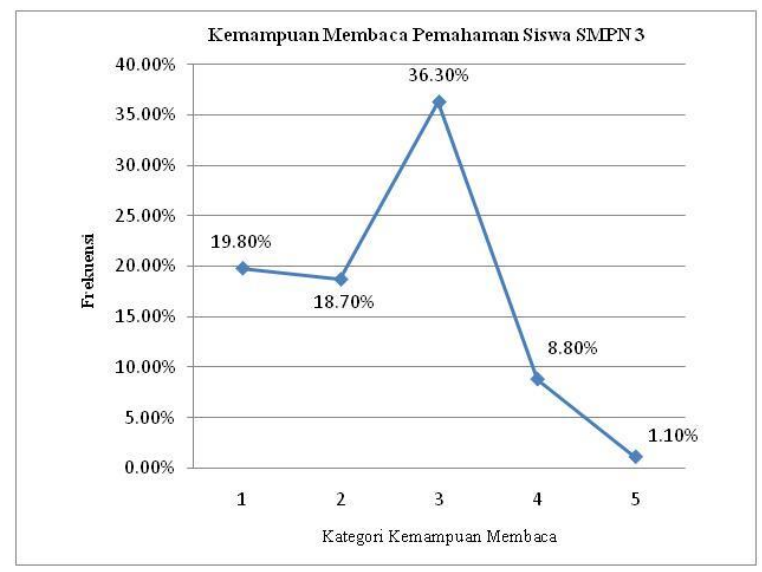

Grafik di atas 38,5\% siswa SMPN 3 Marabahan kemampuan membaca pemahamannya berkategori rendah dan sangat rendah. Modus dari kemampuan membaca pemahaman siswa adalah kategori sedang, yaitu sebesar 36,30\%. Berdasarkan modus dan diagram di atas dapat disimpulkan bahwa kecenderungan kemampuan mem-baca pemahaman siswa berada pada ketegori rendah. Simpulan ini didukung dengan rata-rata kemampuan membaca pemahaman siswa yang terdapat pada Tabel, yaitu sebesar 57,770 yang menunjukkan bahwa kemampuan membaca pemahaman siswa SMPN 3 Marabahan berkategori rendah.
4. Kemampuan membaca kritis siswa SMPN 3 Marabahan

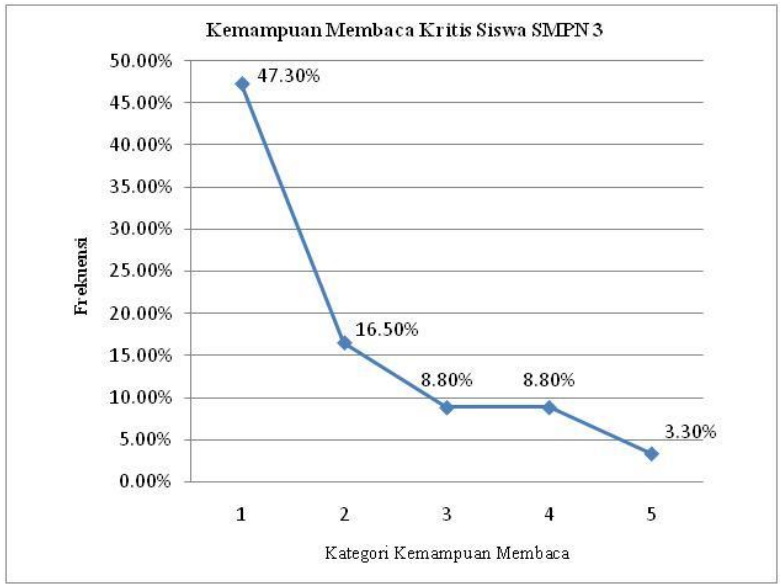

Grafik di atas 63,86\% siswa SMPN 3 Marabahan kemampuan membaca kritisnya berkategori rendah dan sangat rendah. Hanya $12,10 \%$ siswa yang memiliki kemampuan membaca kritis kategori tinggi dan sangat tinggi. Berdasarkan diagram di atas dapat disimpulkan bahwa kecen-derungan kemam-puan membaca kritis sis-wa berada pada ketegori sangat rendah. Simpulan ini didukung dengan rata-rata kemampuan membaca kritis siswa yang terdapat pada Tabel, yaitu sebesar 49,26 yang menunjukkan bahwa kemam-puan membaca kritis siswa SMPN 3 Marabahan berada pada kategori sangat rendah.

\section{Komparasi Kemampuan Membaca Siswa antara SMPN 1 dengan SMPN 3}


Komparasi kemampuan membaca pemahaman dan kemampuan membaca kritis antara siswa SMPN 1 Marabahan dengan siswa SMPN 3 Marabahan akan diuji dengan menggunakan uji-t. Ouput SPSS untuk komparasi dengan menggu-nakan uji-t terdapat pada lampiran 2. Berdasarkan lampiran 2 tersebut, nilai statistik untuk masingmasing parameter dipaparkan beri-kut ini.

\begin{tabular}{|c|r|r|}
\hline $\begin{array}{l}\text { Nilai } \\
\text { Statistik }\end{array}$ & $\begin{array}{l}\text { Kemampuan } \\
\text { Membaca } \\
\text { Pemahaman }\end{array}$ & $\begin{array}{l}\text { Kemampuan } \\
\text { Membaca } \\
\text { Kritis }\end{array}$ \\
\hline F & 0,058 & 3,377 \\
\hline Sig. & 0,810 & 0,068 \\
\hline T & - & - \\
& 6,043 & 2,069 \\
\hline Sig. & 0,000 & 0,000 \\
\hline
\end{tabular}

\section{Korelasi antara Kemampuan}

\section{Membaca Pemahaman dengan}

Kemampuan Membaca Kritis

Output SPSS korelasi dengan korelasi product moment terdapat pada lampiran 3 . Berdasarkan lampiran 3 tersebut, nilai statistik untuk masing-masing parameter dipaparkan Tabel berikut ini.

\begin{tabular}{|l|c|c|r|}
\hline $\begin{array}{l}\text { Nilai } \\
\text { Statistik }\end{array}$ & SMPN 1 & SMPN 3 & $\begin{array}{l}\text { Gabungan } \\
\text { SMPN 1 } \\
\text { dan r } \\
\text { SMPN 3 }\end{array}$ \\
\hline N & 91 & 77 & 168 \\
\hline R & 0,44 & 0,499 & 0,4 \\
& 6 & & 89 \\
\hline Sig. & 0,00 & 0,000 & 0,0 \\
& 0 & & 00 \\
\hline
\end{tabular}

1. Korelasi antara kemampuan membaca pemahaman dengan kemampuan membaca kritis termasuk kategori sedang (lihat tabel interpretasi koefisien korelasi pada lampiran 3)

2. Korelasi antara kemampuan membaca pemahaman dengan kemampu-an membaca kritis termasuk kategori sedang (lihat tabel interpretasi koefisien korelasi pada lampiran 3).

\section{B. Pembahasan}

Dari 6 rumusan masalah mengenai kemampuan membaca pemahaman dan membaca kritis berbeda dengan hipotestis. Pada hipotesis pertama kemampuan membaca pemahaman SMPN 1 Marabahan diduga tinggi sedangkan skornya kategori sedang. Hipotesis kedua kemampuan 
membaca kritis SMPN 1 Marabahan diduga tinggi sedangkan skornya kategori rendah.

Hipotesis ketiga kemampuan membaca pemahaman SMPN 3 Marabahan diduga sedang sedangkan skornya rendah. Hipotesis keempat kemampuan membaca kritis SMPN 3 Marabahan diduga sedang sedangkan skornya sangat rendah.

Hipotesis kelima terdapat perbedaan hasil kerja siswa SMPN 1 dan SMPN 3, hipotesis sesuai. Dikarenakan hasil kemampuan membaca SMPN 1 yang diduga tinggi ternyata kurang lebih dengan SMPN 3, yaitu rendah, sedang, dan sangat rendah. Hipotesis keenam terdapat hubungan selaras antara membaca pemahaman dengan membaca kritis, hipotesis sesuai. Dikarenakan pembaca yang memahami suatu bacaan berkaitan dengan mampu tidaknya membaca kritis dengan analisis.

\section{Simpulan dan Saran}

\section{Simpulan}

Membaca merupakan aktivitas memahami tulisan (Nurgiyantoro 1995:224). membaca merupakan proses pemahaman seorang pembaca terhadap makna lambanglambang tertulis (Harjasujana 1996:5). Kemampuan membaca merupakan usaha yang paling penting harus dikerjakan oleh pelajar (Rahim 2008:1). Membaca merupakan kegiatan untuk mendapatkan informasi (Munaf 2008:3). Membaca secara kritis berarti harus membaca secara analisis dengan penilaian (Agustina 2008:124).

Dari uraian deskripsi hasil penelitian terdapat beberapa simpulan, berikut. Kemampuan membaca kritis siswa SMPN di Kabupaten Barito Kuala berada pada kategori rendah. Kemampuan membaca pemahaman siswa SMPN 1 Marabahan berada pada kategori sedang dengan rata-rata kemampuan membaca kritis sebesar 68,00. Kemampuan membaca kritis siswa SMP Negeri 1 Marabahan berada pada kategori rendah dengan rata-rata kemampuan membaca kritis sebesar 55,00.

Kemampuan membaca pemahaman siswa SMP Negeri 3 Marabahan rendah sebesar 57,77 . Kategori sangat rendah dengan ratarata ke-mampuan membaca kritis sebesar 49,26 .

Terdapat perbedaan yang signifikan kemampuan membaca pemahaman dan kemampuan membaca kritis. Terdapat korelasi signifikan antara kemampuan membaca pemahaman dan kemampuan membaca kritis siswa SMP Negeri 1 Marabahan dan SMP Negeri 3 Marabahan. 
Saran

Hasil penelitian ini layak ditindaklanjuti dengan penelitian sejenis. Misalnya, penelitian tentang teknik meningkatkan membaca pemahaman dan membaca kritis diterapkan dalam proses pembelajaran membaca di SMPN Kabupaten Banjar.

\section{Daftar Pustaka}

Agung, Ngurah I Gusti. 2002. Analisis Hubungan Kausal Berdasarkan Data Kategotik. Jakarta: PT. Raja Grafindo Persada.

Agustina. 2008. Pembelajaran Keterampilan Membaca. Padang: Jurusan Bahasa dan Sastra Indonesia dan Daerah. Padang: Universitas Negeri Padang.

Ahuja, Pramila dan G.C. Ahuja. 2010. Membaca secara Efektif dan Efesien. Bandung: Buku Utama.

Arief Muttaqiin, Wahyu Sopandi. 2015. "Hubungan Antara Kemampuan Membaca Kritis dalam Pembelajaran Penemuan dan Kemampuan Berpikir Kritis Siswa". (Dalam Jurnal Ilmu Pendidikan dan Pengajaran, Vol. 2 No. 2, Juli 2015). Gorontalo: Universitas Negeri Gorontalo.

Arikunto, Suharsimi. 2002. Prosedur Penelitian Suatu Pendekatan Praktik (Revisi V). Jakarta: Rineka Cipta.

Arikunto, Suharsimi. 2010. Prosedur Penelitian Suatu Pendekatan Praktik. Jakarta: Rineka Cipta.
Banjarmasin, FKIP ULM. 2016. Pedoman Penulisan Karya Ilmiah. Banjarmasin: Universitas Lambung Mangkurat Banjarmasin.

Cornelius, Trihendradi. 2007. SPSS Statistik Inferen: Teori Dasar dan Aplikasi. Yogyakarta: Andi Offset.

Departemen Pendidikan Nasional. 2003. Undang-undangSisdiknas.

Jakarta:Universitas Terbuka.

Hadi, Sutrisno. 2000. Analisis Regresi. Yogyakarta: Andi Offset.

Harjasujana, Ahmad. 1998. Materi Pokok Membaca: Buku Ajar. Jakarta: Kurnika Universitas Terbuka.

Helfani, Rani. 2013. Hubungan Kemampuan Membaca Kritis Dengan Kemampuan Menulis Paragraf Argumentasi Siswa Kelas VII SMP Negeri 1 Sawahlunto. Padang: Universitas Negeri Padang.

Jumadi, 2018. Kemampuan Membaca Siswa SMP yang bermukim di Sekitar Sungai di Kota Banjarmasin. Dalam Jurnal Bahasa, Sastra, dan Pembelajarannya. 8 (2): 234-244.

Jumadi. W. 2009. Belajar dan Pembelajaran. Jakarta: Rineka Cipta.

Maharani. 2017. "Meningkatkan Pemahaman Membaca Siswa Melalui Strategi Affinity dan Materi Bacaan Otentik Siswa Kelas X IIS 2 SMA Negeri 7 Denpasar." Dalam Jurnal Bakti Saraswati Vol. 4, No. 1 Maret 2015. ISSN: 2088-2149. Hlm 9. Denpsar: Universitas Udayana. 
Malang. IKIP. 2010. Pedoman Penulisan Karya Ilmiah. Malang: Universitas Negeri Malang.

Munaf, Yarni. 2005. Pengajaran keterampilan Membaca. Buku Ajar. Padang: Fakultas Bahasa Sastra dan Seni. Universitas Negeri Padang.

Nurgiyantoro, Burhan. 1995. Penelitian dalam Pengajaran Bahasa dan Sastra. Yogyakarta: BPFE.

Nurhadi. 1987. Membaca Cepat dan Efektif. Bandung: C.V. Sinar Baru Bandung.

Nurhadi. 2009. Dasar-dasar Teori Membaca. Malang: Universitas Negeri Malang.

Pratista, Arif. 2018. Aplikasi SPSS 10.05 dalam Statistik dan Rancangan Percobaan. Bandung: Alfabeta.

Putri Nur Ramadani, Irfani Basri, Emidar. 2013. "Hubungan Kemampuan Membaca Kritis Dengan Kemampuan Menulis Argumentasi Siswa Kelas VIII SMP Negeri 7 Pariaman". Dalam Jurnal Pendidikan Bahasa dan Sastra Indonesia, Vol. 1 No. 2 Maret 2013; Seri G 477-562. Padang: Fakultas Bahasa Sastra dan Seni. Universitas Negeri Padang.

Rahimi, Faridah. 2008. Pengajaran Membaca di Sekolah Dasar. Jakarta: Sinar Grafika.

Somadyo, Sams. 2011. Strategi dan Teknik Pembelajaran Membaca. Yogyakarta: Graha Ilmu.

Sugiyono. 2007. Statistika untuk Penelitian. Bandung: Alfabeta.
Syafi'ie, Imam. 1999. Pengajaran Membaca di Kelas-kelas Awal Sekolah Dasar. Malang: Universitas Negeri Malang.

Tampubolon. 1998. Kemampuan Membaca Teknik Membaca Efektif dan Efisien. Bandung: Angkasa.

Tarigan, Hendry Guntur. 2008. Membaca: sebagai Suatu Keterampilan Berbahasa. Bandung: Angkasa.

UNESCO Institute for Statistics. 2008. International Literacy Statistics. A Review of Cocepts, Methodology, and Current Data. Montreal, Canada: UNESCO Institute for Statistics.

Wiratna Sujarweni, Poly Endrayanto. 2012. Statistika Penelitian. Yogyakarta: Graha Ilmu.

Yousda, Ine I. Amirman, Zainal Arifin. 1993. Penelitian dan Statistik Pendidikan. Jakarta: Bumi Aksara. 